Original Contribution

\title{
INVESTIGATION OF THE MODULATORY ROLE OF BULGARIAN MENTHA PIPERITA L. OIL AGAINST RADIATION-INDUCED OXIDATIVE DISORDERS AND ANTIOXIDANT STATUS IN VITRO
}

\author{
Y. D. Karamalakova* \\ Department of Chemistry and Biochemistry, Medical Faculty, Trakia University, \\ Stara Zagora, Bulgaria
}

\begin{abstract}
This investigation report on the free radical-scavenging and radio-modulatory properties of Bulgarian M. piperita L. oil. The chemically pure oil $(97 \%)$ was tested alone and after expositer to ultraviolet radiation (290-320 $\mathrm{nm}$ ) and gamma radiation at doses of 5, 10, 20 and $30 \mathrm{~Gy}$. The in vitro antioxidant status studied by different spectrophotometrically methods of $M$. piperita alone was found to be lower compared to UVB and 10 Gy radiated oil. By direct EPR spectroscopy, single almost symmetrical EPR signals were registered in oil alone $(\mathrm{g}=2.00492 \pm 0.0003), \mathrm{UVB}(\mathrm{g}=2.00586 \pm 0.0002)$ and 10 Gy irradiated $(g=2.0019 \pm 0.0002)$ samples. Antioxidant activity and radical scavenging capacity of $M$. piperita oil alone and after radiation was also evaluated by the DPPH test. The intensities of the EPR signals of $M$. piperita oil alone, and irradiated samples demonstrated the possible formation of stable radical structures. The EPR spectra considerably higher after radiation, and excellent DPPH scavenging capacity exhibited by $M$. piperita indicate good antioxidant potential, radio-modulatory activity and prevent effectively radiation-induced oxidative disorders.
\end{abstract}

Key words: $M$. piperita, EPR, Radiation, Oxidative disorders

\section{INTRODUCTION}

Widespread evidences indicate that exposure to ionizing and non-ionizing radiation results in significant changes in biological systems, viz., DNA, carbohydrates, polyunsaturated membrane and proteins, and caused increase in free radicals levels [1]. Ionizing radiationinduced reactive oxygen species (ROS) and reactive nitrogen species (RNS) such as superoxide anion radicals $\left(\mathrm{O}_{2}{ }^{-}\right)$, hydroxyl radicals ( $\mathrm{HO} \cdot)$, hydrogen peroxide $\left(\mathrm{H}_{2} \mathrm{O}_{2}\right)$, peroxyl radicals ( $\mathrm{RCOO} \cdot$ ) and $\mathrm{NO} \cdot$ radicals are active oxygen/ nitrogen components that are detoxified by endogenous antioxidant system [2]. After radiation exposure it is possible to generate excessive amounts of ROS and RNS, where the detoxifying cellular enzymatic and non-enzymatic mechanisms [3] in the body are insufficient. This unleashes pro-oxidant processes leading to oxidative stress (OS), irreversible cell dysfunction and cell death [4]. Over the last 20 years, antioxidants have been subjected to numerous studies related to their

\footnotetext{
*Coresspondence to: Yanka Karamalakova, PhD, Department of Chemistry and Biochemistry, Medical Faculty, Trakia University, 11 Armeiska Str., 6000 Stara Zagora, Bulgaria, Bykaramalakova@gmail.com
}

inhibition of the oxidation reaction effect, reducing the frequency of oxidative stressdisorders, associated with exposure to ionizing radiation (IR). Therefore, attention has been focused on the use of essential oils and their phytochemicals, for radical-scavenging activity and reduction in the radiation-induced ROS/ RNS and improvement of health $[5,6]$.

Peppermint in East Europe commercially grown for production of essential oil for pharmaceutical properties, body lotions, lip balms and dry leaves were used for herbal tea. Bulgarian Mentha piperita L. (Peppermint, $M$. piperita, Lamiaceae family), is a cultivated natural hybrid of Mentha sivestris L.,Mentha longifolia L., Mentha viridis L., Mentha aquatica L., also known as a hybrid mint or 'Bulgaro- Michum'. It is a unique plant species with high quality $[7,8,9]$. The main constituents in extracted oil was monoterpene menthol (66.4 - 68\%) (represented in free form menthol, isomenthol, and neomenthol), and carboxyl esters, particularly- menthyl acetate [9]. The oil also contains small amounts of many additional compounds including menthone, $a$-pinene, $\quad b$-pinene, sabinene, limonene, myrcene, cineole, $a$ - and 
$g$ - terpinene, hexanol, caryophyllene, pulegone and ets $[9,10]$.

Many investigators reported that $M$. piperita extract have several important properties including antioxidant, radical-scavenging, antibacterial $[6,11,12]$, intestinal, neuronal, and cardiac preparations [13] vasodilatation, irritation, hyper secretion, influenced drug effects [14, 15]. Oral administration of $M$. piperita extract protected mice against the radiation-induced sickness $[14,16]$. For the first time observed that the chloroform/ mint extract protected against the $\gamma$-radiationinduced oxidative stress and mortality $[7,16]$. Also, was shown that the $M$. piperita extract possesses significant radioprotective properties $[16,17]$ in patients undergoing cancer treatment [7], and for reduction in irritable bowel syndrome (IBS) symptoms [18, 19] and anticancer properties [20].

IR is recognized method for maintaining the quality of aromatic herbs, oils, spices and vegetable, for a long time (Directive 1999/3/EC) [21]. Increased antioxidant activity was observed in essential oils derived from pre-irradiated leaves and fruits [22, 23]. Statistical analyses of antioxidant effects of UVB and gamma $(\gamma)$ radiation on the content of volatile oils in spices showed that there were significant differences between $\gamma$-radiated and samples alone [22-24].

The usage of in vitro and in vivo model systems, serve as models for preliminary observations in the evaluation of pharmacological activities, radiation-induced oxidative changes in chemical composition and different EPR spectrum shapes as a function of temperature and time $[23,25,26]$.

Keeping in view the multifarious properties of M. piperita, the present study was focused to find out the radioprotective properties of essential oil with a view to elucidating the mechanism of action, using a standard spectrophotometrically and Electron Paramagnetic Resonance technique (EPR) in vitro models.

\section{MATERIALS AND METHODS \\ Isolation and characterization of $M$. piperita oil}

The plant mass was collected early in the morning from experimental plots of $25 \mathrm{~m}^{2}$ in 4 replicates. $M$. piperita plants were irrigated during a vegetative period to maintain $70-80 \%$ of the FWC. M. piperita was collected in full flowering form $[8,9,10,12]$. The essential oil content in the biomass for the analyses was measured using hydrodilation in Clevenger
Apparatus. M. piperita oil (purity 97\%) was provided by "Institute for roses and aromatic plants" Kazanlak, Bulgaria [8, 9, 10, 12].

\section{Chemicals}

2,2-dipheniyl-1-picrylhydrazyl

(DPPH),

Quercetin, 2,2-azinobis (3ethylbenzothiazoline-6-sulfonic acid) sulfanilamide, Naphthylethylenediamine, Cholesterol (1:1 molar ratio), Soyalecithin were purchased from Sigma Chemicals, USA. Deionized and distillated water was used for all experiments. Other chemicals used were analytical or HPLC grade.

\section{Irradiation}

$M$. piperita oil samples (in de-aerated capillary) were exposed to UVB ( $U V$-vis Transilluminator- 4000, Bulgaria; 290-320 $\mathrm{nm}$; two lamps; 220V $50 \mathrm{~Hz}$; microwave power 7.70VA; for 2 hrs rate; humidity- $40 \%$ ) and to ${ }^{60} \mathrm{Co}$ radiation at dose $5,10,20,30 \mathrm{~Gy}$ using $\gamma$ - chamber Gamma Cell 5000 (dose rate of $1.37 \mathrm{~Gy} / \mathrm{h}$, Board of Radiation and Isotope Technology, India). Dosimetry was carried out using Baldwin Farmer's secondary dosimeter and Fricke's Chemical Method and all the radiation safety measures were strictly followed during experimentation. Fresh air was circulated in the chamber throughout the course of irradiation.

\section{ANTIOXIDANT ACTIVITY}

\section{Reducing Power Assay}

The reducing power potential of UVB and $\gamma$ irradiated samples and oil alone, was determined by the method of Oyaizu, 1986 [27]. A $50 \mu \mathrm{g} / \mathrm{ml}$ concentration of $M$. piperita oil alone, after UVB, and 5, 10, 20, 30 Gy irradiation was firstly tested to determine the concentration at which oil exhibited maximal reducing potential both, immediately and 24 hours post irradiation. The reaction mixture was left for 10 minutes at room temperature $\left(27^{\circ} \mathrm{C}\right)$ and the absorbance was measured at $700 \mathrm{~nm}$. An increased absorbance of the reaction mixture indicates increased reducing power:

\%Inhibition $=\left[\left(O D_{\text {control }}-O D_{\text {test }}\right) / O D_{\text {control }}\right] x 100$

\section{DPPH radical- scavenging activity}

Radical scavenging activity of UVB and $\gamma$ irradiated (5, 10, 20, 30 Gy) samples and $M$. piperita oil alone against the stable DPPH radical was determined according to Cuendet at all, 1997 [28], with modifications. Briefly, $1.0 \mathrm{ml}$ of DPPH $(100 \mu \mathrm{M})$ was added to 50 $\mu \mathrm{g} / \mathrm{ml}$ volume concentration of the studied samples. Mixtures were incubated in the dark for $10 \mathrm{~min}$ and their absorbance at $517 \mathrm{~nm}$ was measured. Quercetin was used as a positive 
control. The percent of DPPH radicals scavenged was calculated according to the equation:

$\%$ Inhibition $=\left(A_{\text {control }}-A_{\text {test }}\right) / A_{\text {control }} \times 100$

\section{Non-enzymatic antioxidant $\left(\right.$ ABTS $\left.^{++}\right)$ radical-scavenging assay}

The ABTS $^{*+}$ diammonium salt radical cation decolourization test is also a radicalscavenging test. $\mathrm{ABTS}^{\circ+}$ assay of UVB and 5, 10, 20, 30 Gy $\gamma$ - irradiated samples and $M$. piperita alone $(50 \mu \mathrm{g} / \mathrm{ml}$ volume $)$ was performed by Re et al., 1999 [29] with slight modifications. The reaction mixtures were incubated at $24^{\circ} \mathrm{C}$ for $30 \mathrm{~min}$ and the intensity of chromogen was measured at $734 \mathrm{~nm}$ against PBS as control. Antiradical activity of examined sample was presented as the percentage of $\mathrm{ABTS}^{\circ+}$ radical scavenging and calculated according to the equation:

$\%$ Inhibition $=\left(A_{\text {control }}-A_{\text {test }}\right) / A_{\text {control }} \times 100$

\section{RADIATION PROTECTION ACTIVITY IN LIPID PHASE}

Nitric oxide ( $\mathrm{NO}^{-}$) ion scavenging assay

The presence of nitrite potential, a stable oxidized product of nitric oxide ( $\mathrm{NO}^{-}$) of UVB and 5, 10, 20, 30 Gy $\gamma$-irradiated samples and $M$. piperita alone $(50 \mu \mathrm{g} / \mathrm{ml})$ was determined according to the standard methodology described by Shirwaikar et al., 2006 [30]. The scavenging potential was evaluated as decrease in percent absorbance of the chromogen formed by diazotisation of nitrite with sulfanilamide and subsequent coupling with naphthylethylenediamine recorded at $546 \mathrm{~nm}$.

\section{Membrane protection activity against radiation- induced damage}

Cholesterol and Soyalecithin (1:1 molar ratio) were suspended in an appropriate amount of chloroform. A thin film was developed by complete evaporation of chloroform in a rotary evaporator (Buchi, New castle, USA) at $40^{\circ} \mathrm{C}$. The film was subjected to hydration in $(0.1 \mathrm{M}$, $\mathrm{pH}$ 7.4) $\mathrm{PBS}$ and were incubated in $\left(40^{\circ} \mathrm{C}\right)$ water bath for $4 \mathrm{hr}$. The stock solution was diluted with PBS to the final concentration in terms of phospholipid content [31]. Different treated oil samples, liposome only (untreated), radiation only $(2.5 \mathrm{~Gy})$, liposome $+M$. piperita oil and liposome $+M$. piperita oil $+2.5 \mathrm{~Gy}$ were evaluated for the levels of malondialdehyde, the final product of membrane degeneration. A radiation dose of $2.5 \mathrm{~Gy}$ at a dose rate $1.37 \mathrm{kGy} / \mathrm{h}$ was used and after exposure the samples immediately were incubated for $1 \mathrm{~h}$ at $37^{\circ} \mathrm{C} .10 \%$ TCA and $0.5 \%$ thiobarbituric acid, 1:1 ratio and $0.025 \mathrm{M}$ $\mathrm{NaOH}$ were added. The mixture was heated in
KARAMALAKOVA Y. D. water bath $\left(80^{\circ} \mathrm{C}\right)$ for $1 \mathrm{~h}$ and absorbance was measured at $535 \mathrm{~nm}$ [32].

\section{ELECTRON PARAMAGNETIC RESONANCE SPECTROSCOPY (EPR) ANALYSIS \\ In vitro direct EPR studies on M. piperita oil alone and after $U V$ or $\gamma$-irradiation}

EPR experiments were carried out an X-band EMX $^{\text {micro }}$ spectrometer (Bruker, Germany) equipped with standard resonator. Spectral processing ( $g$-value calculation) was performed with Bruker WIN-EPR and SimFonia software. Spectra of $M$. piperita oil alone were at following settings: center field 3514.00- $3516.00 \mathrm{G}$, sweep width $200.00 \mathrm{G}$, microwave power $0.634-3.323 \mathrm{~mW}$, modulation amplitude 1.00- $5.00 \mathrm{G}$, gain $1 \times 10^{5}$, time constant $1310.72 \mathrm{~ms}$, sweep time $5.24 \mathrm{~s}, 1$ scan per sample. The EPR settings for the UVB and $\gamma$-irradiated samples were the same, only the modulation amplitude was reduced to $1.00-5.00 \mathrm{G}$.

\section{EPR determination of DPPH radical scavenging activity}

By studies according to Santos et al., 2009 [33] with slight modifications Zheleva et al., 2012 [34] was determine the ability to scavenge stable DPPH radical. $M$. piperita oil $(50 \mu \mathrm{g} /$ $\mathrm{ml}$ ) alone, UVB and $\gamma$-irradiated samples was added to $250 \mu \mathrm{l}$ ethanol solution of DPPH $(80 \mu \mathrm{mol} / \mathrm{l})$. After $10 \mathrm{~min} /$ dark incubation at $25^{\circ} \mathrm{C}$ samples were transferred into the EPR cavity, and the scavenging ability was calculated as follows:

Scavenged DPPH radicals $(\%)=\left[\left(I_{0}-I\right) / I_{0}\right] \times 100$,

where $\mathbf{I}_{\mathbf{0}}$ is the integral intensity of the DPPH signal of the control sample and $\mathbf{I}$ is the integral intensity of the DPPH signal after addition of the tested oil sample to the control sample.

The control samples contained $250 \mu \mathrm{l}$ of $\mathrm{DPPH} /$ ethanol solution $+50 \mu \mathrm{l}$ ethanol. The settings were as follows: center field $3516.00 \mathrm{G}$, sweep width $200.00 \mathrm{G}$, microwave power $3.232 \mathrm{~mW}$, modulation amplitude $5.00 \mathrm{G}$, receiver gain $5.02 \times 10^{3}$, time constant $163.84 \mathrm{~ms}, 1$ scan per sample.

\section{STATISTICAL ANALYSIS}

Statistical analysis was performed with Statistica 6.1, StaSoft, Inc. and results were expressed as means \pm standard error (SE). Statistical significance was determined by the Student's t-test. A value of $p<0.05$ was considered statistically significant. 


\section{RESULTS and DISCUSSION}

Plethora of essential oils and herbal extracts was screened to minimize UVB and $\gamma$ radiation induced oxidative changes and degradation of macromolecules and membrane-lipids peroxidation, after radiotherapy or unplanned radiation exposures $[1,35,36]$. The oxidation of membrane macromolecules leads to persistent oxidative disturbances, obstruction of intracellular processes, may result in tumor formation and oxidative stress [36]. Therefore, it is necessary to observe an effective radiation-protected natural antioxidant, supporting delaying or inhibiting cellular damages, mainly through the properties of free radical extraction [36]. Thus, M. piperita L. essential oil was evaluated for its in vitro stable
KARAMALAKOVA Y.D. antioxidant activity, scavenging of ROS/RNS [37] and radiation- modulative properties.

The reducing power potential is generally associated with the presence of reductants, which exert antioxidant activity by breaking the radical chains by donating an electron [38]. Maximal reducing power for $M$. piperita alone at $50 \mu \mathrm{g} / \mathrm{ml}$ concentration was $0.245 \pm 0.036$ $\%$. After exposure of UVB, oil exhibited higher reducing power $(0.346 \pm 0.006 \%)$, compared to oil alone $(0.245 \pm 0.036 \%)$. Maximum reducing ability was found for 10 Gy sample $(0.474 \pm 0.021 \%)$, compared to $M$. piperita alone $(0.245 \pm 0.036, \mathrm{p}<0.05) . M$. piperita possess good reducing potential towards $\mathrm{Fe}^{3+}$ complex as after UVB up to 10 Gy (Figure 1).

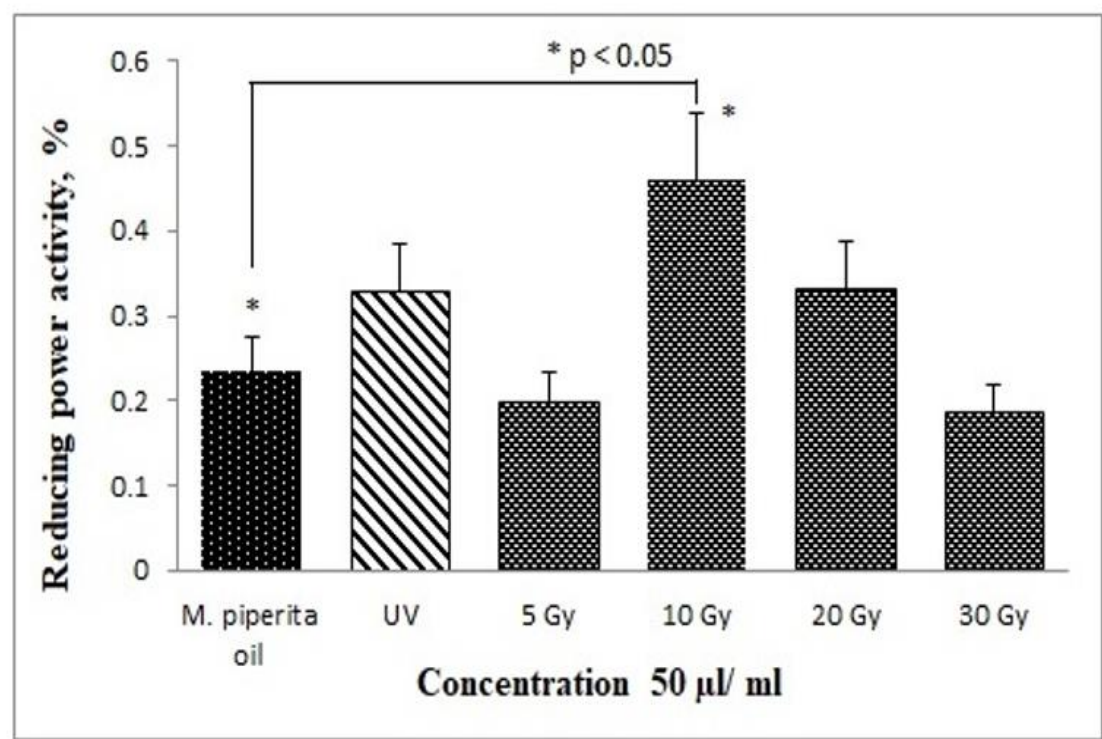

Figure 1. The percent reducing power potential (\%) of M. piperita oil alone and after UV and 5-30 Gy $\gamma-$ radiation. Results are expressed as mean of replicates (in thrice) from three independent experiments. $\left.{ }^{*}\right)$ Significants $(\mathrm{p}<0.05)$ as compared to M. piperita oil alone.

Results of 24h post-irradiation treatment of $M$. piperita samples showed significantly decrease in percent reducing power potential compared to oil alone and to samples measured immediately following irradiation (results not shown). IR increases the iron loading in the cellular environment resulting in hemolysis [38]. Probably, M. piperita exhibits antioxidant protection to overcome radiation- oxidative disorders in vivo, by reducing $\mathrm{Fe}^{3+}$ to less harmful $\mathrm{Fe}^{2+}$ cations.

Figure 2 indicate in vitro DPPH radical inhibitory effect was found to be strongest in 10 Gy irradiated $M$. piperita samples $(83.52 \%$ DPPH, $\mathrm{p}<0.05$ ) with slight difference in case of UVB irradiated $M$. piperita samples $(79.4 \%$ DPPH, $\mathrm{p}<0.04)$ and $M$. piperita alone $(73.7 \%$ DPPH, $\mathrm{p}<0.05)$ at concentration $50 \mu \mathrm{g} / \mathrm{ml}$, compared to positive control. Previous studies showed that menthol is the main component of $M$. piperita oil [12, 40, 41] and menthone, limonene and methyl acetate as second components, were responsible for scavenging effectiveness towards DPPH radicals and good antioxidant activity of oil [12, 42]. Considerable increase in DPPH- radical scavenging of the $M$. piperita oil at UVB and 10 Gy radiations could be explained with unchanged stable structures in compound as menthol, menthone, limonene and methyl acetate which probably largely determine its antioxidant activity [43].

The total antioxidant activity of oil-hydrogenreleasing antioxidants and those derived from lipid-peroxyl radicals are readily stained by the ABTS free radical scavenging models method [42].

At $50 \mu \mathrm{g} / \mathrm{ml}$, both UV $(43.1 \pm 1.41 \%)$ and 10 Gy irradiated (58.44 $\pm 1.33 \%)$ samples (Figure 3) exhibited increase in scavenging abilities towards ABTS $\bullet+$, compared to $M$. 
piperita alone $(41.87 \pm 0.91 \%)$. Only at $10 \mathrm{~Gy}$ irradiated $(58.44 \pm 1.33 \%$; $<0.05)$ samples were established significant increases in ABTS $^{++}$scavenging, compared to standard.
KARAMALAKOVA Y. D. According to Singh, Shushni and Belkheir [44], M. piperita has high ABTS inhibitory potential, due to the content of menthol, methyl acetate and etc.

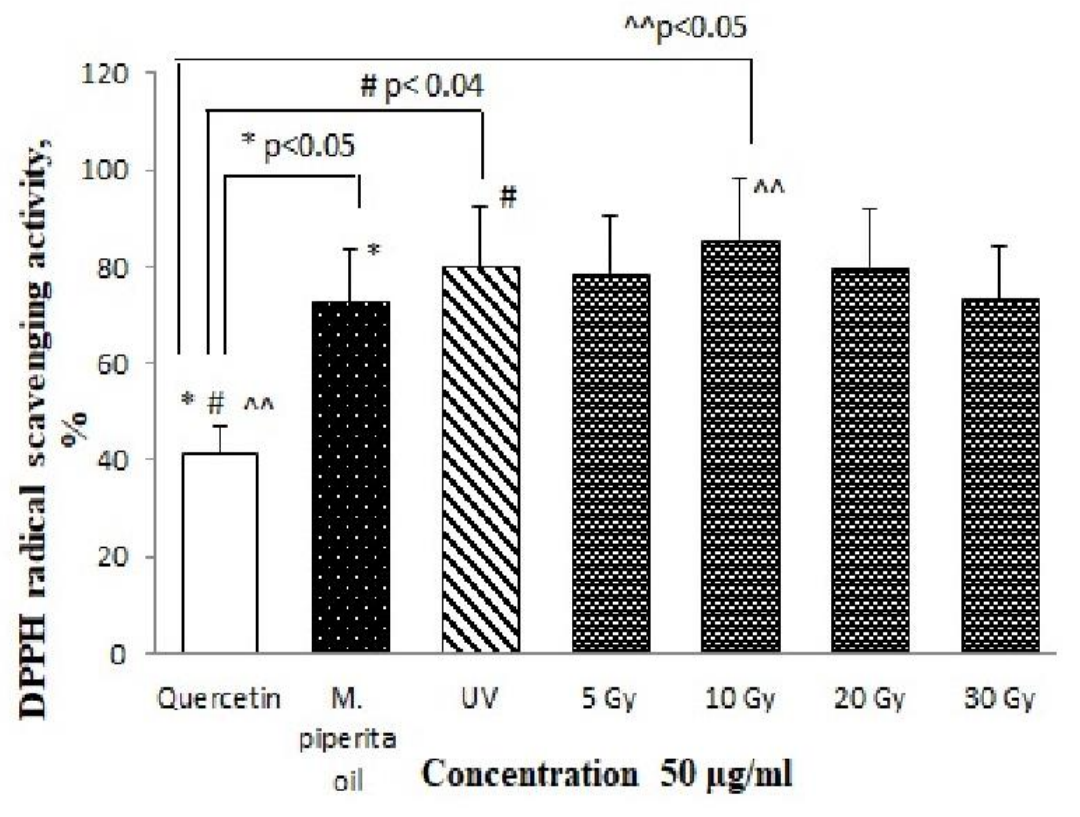

Figure 2. The DPPH- radical scavenging activity (\%) of M. piperita oil alone and after UV and 5-30 Gy $\gamma-$ radiation. Results are expressed as mean of replicates (in thrice) from three independent experiments.

Significants $\left({ }^{*} \mathrm{p}<0.05 ;{ }^{\#} \mathrm{p}<0.04 ;{ }^{\wedge} \mathrm{p}<0.05\right)$ as compared to Quercetin, as positive control.

Essential oils were widely used as oxidationfood protectors and can serve as radicalscavengers in the pharmaceutical and cosmetic industries, especially neutralizing radiation. On the other hand, Jordan et al. [45] reported that essential oils containing $\alpha$ - and $\gamma$-terpene, terpinolein, etc., were capable of donating hydrogen atoms to stabilize $\mathrm{ABTS}^{*+}$. These components predominate in the $M$. piperita in this study at very low concentrations. Probably, this fact explains the low observed inhibitory activity of the oil alone, compared to the quercetin, as positive control.

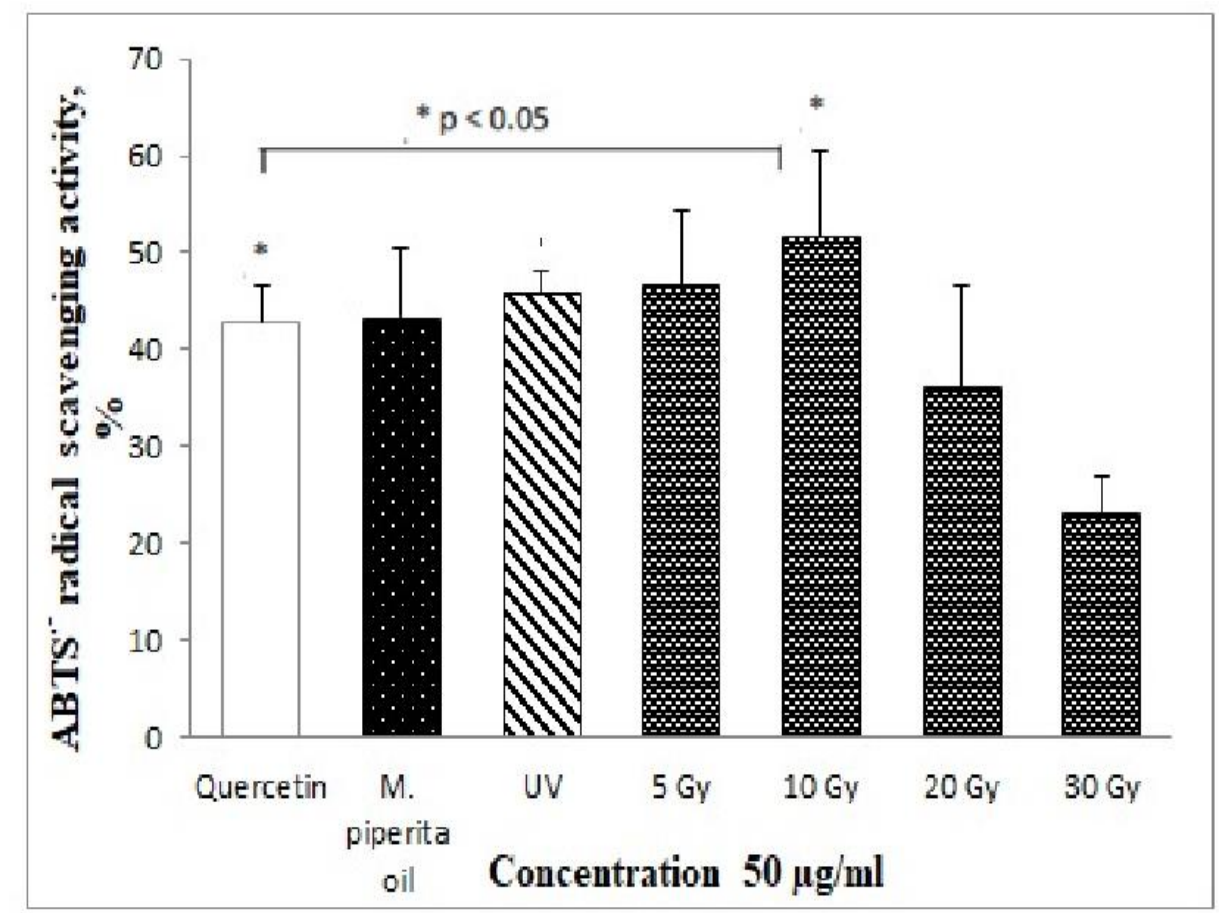

Figure 3. The $\mathrm{ABTS}^{\circ+}$ radical scavenging activity (\%) of M. piperita oil alone and after UV and 5-30 Gy $\gamma-$ radiation. Results are expressed as mean of replicates (in thrice) from three independent experiments. ${ }^{*}$ ) Significants $(\mathrm{p}<0.05)$ as compared to Quercetin as positive control. 
The past decades have identified nitrogen oxide $\left(\mathrm{NO}^{\circ}\right)$ as reactive nitrogen species (RNS), important molecule messenger/ plant growth regulator, whose concentration increases during oxidative cellular damages, but also during specific plant development processes $[46,47]$. $\mathrm{NO}^{\circ}$ scavenging ability against (Figure 4) increases with increase the radiation of $10 \mathrm{~Gy}$. At $50 \mu \mathrm{g} / \mathrm{ml}$ maximum $\mathrm{NO}$ • scavenging activity were $79.11 \pm 3.1 \%, \mathrm{p}<$ 0.05 for UVB samples and $89.92 \pm 7.01 \%$, $\mathrm{p}<0.05$ for 10 Gy irradiated samples, compared to $M$. piperita alone $(59.92 \pm 5.61 \%)$. In vitro tested samples of $M$. piperita alone and after
KARAMALAKOVA Y. D. raditaion reduced $\mathrm{NO}^{\circ}$ production indicating that oil contains hydrophilic antioxidant substances possessing $\mathrm{NO}^{\circ}$ scavenging ability. Furthermore, for tested samples of UVB and 10 Gy oil, showed higher scavenging activity compared to $M$. piperita alone, suggesting that after radiation a new additional structures were involved in reducing of $\mathrm{NO}^{\circ}$ radicals levels.

Pathologically, IR induced oxidative disorders generates $\mathrm{NO}^{\circ}$, and play a critical role in initiation and progression of pro-oxidative damages and dysfunction of the nervous system, as well [48].

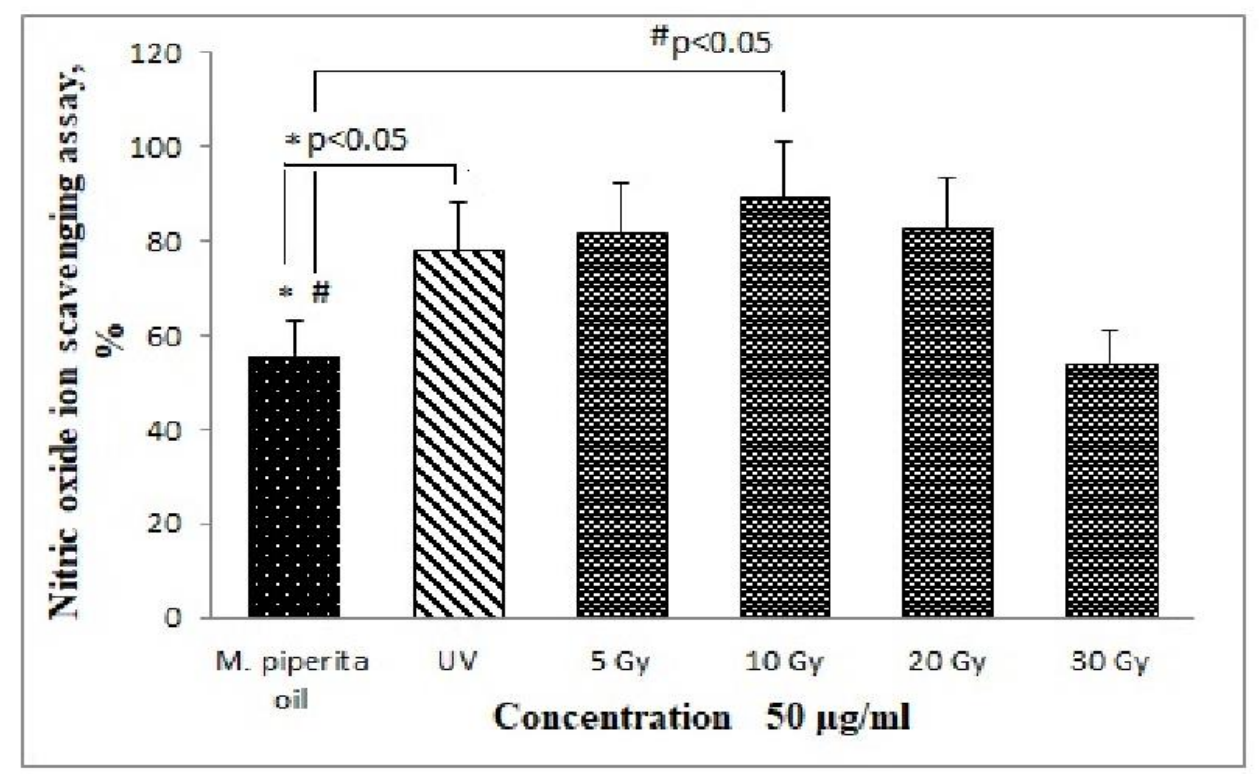

Figure 4. The Nitric oxide radical scavenging activity (\%) of $M$. piperita oil alone and after UV and 5-30 Gy $\gamma$-radiation. Results are expressed as mean of replicates (in thrice) from three independent experiments. (*, \#) Significants ( $\mathrm{p}<0.05)$, as compared to oil alone.

Samarth and Kumar, 2003 and Samarth et al., 2004 [14, 49] comment that M. piperita extract has been radioprotective in whole-body of animals when administered prior to 8-10 Gy of $\gamma$-radiation exposure. Also, $\mathrm{O}_{2}{ }^{-}$anion reacts with $\mathrm{NO}^{\bullet}$ radicals to serious toxic products affecting protein, lipids and neurons [50]. Bearing in mind, $M$. piperita extracts exhibits antioxidant- scavenging activity, Kma L, 2014 [51] show that $M$. piperita could be used as neuron-protective agent against radiationinduced apoptosis in the central nervous system.

In fact, natural flavonoids and polyphenols have potential to inhibit lipid peroxidation by suppression of highly-reactive lipid-peroxyl radicals and reduce iron in lipooxygenase enzyme and thus prevent initiation of lipid peroxidation reaction [52]. The membrane system (artificial liposomes) was utilized to estimate the possibility of $M$. piperita oil to protect the membrane lipids of liposomes against 2.5 Gy peroxidation (dose rate $=1.26$ $\mathrm{KGy} / \mathrm{hr}$ ). The most effective dose for inhibition of peroxidation in the tested liposome system was $100 \mu \mathrm{g} / \mathrm{ml}$. M. piperita oil exhibited significantly higher membrane protection at $150 \mu \mathrm{g} / \mathrm{ml}(0.0696 \pm 0.34 \%$; $* * \mathrm{p}<0.04)$. The test region at $100-150 \mu \mathrm{l} / \mathrm{ml}$ of 2.5 Gy was registered maximal lipidperoxidation protection (Figure 5). 2.5 Gy $M$. piperita samples indicated two times higher anti-lipid peroxydation, compared to $M$. piperita alone. We assume, that the highest membrane protection after IR, due to the chelation of transition metal ions [53]. Good ability of leaf extract of $M$. piperita to significant decrease in malondialdehyde inhibition in liver homogenates after radiation is in agreement with our reported results [54]. 


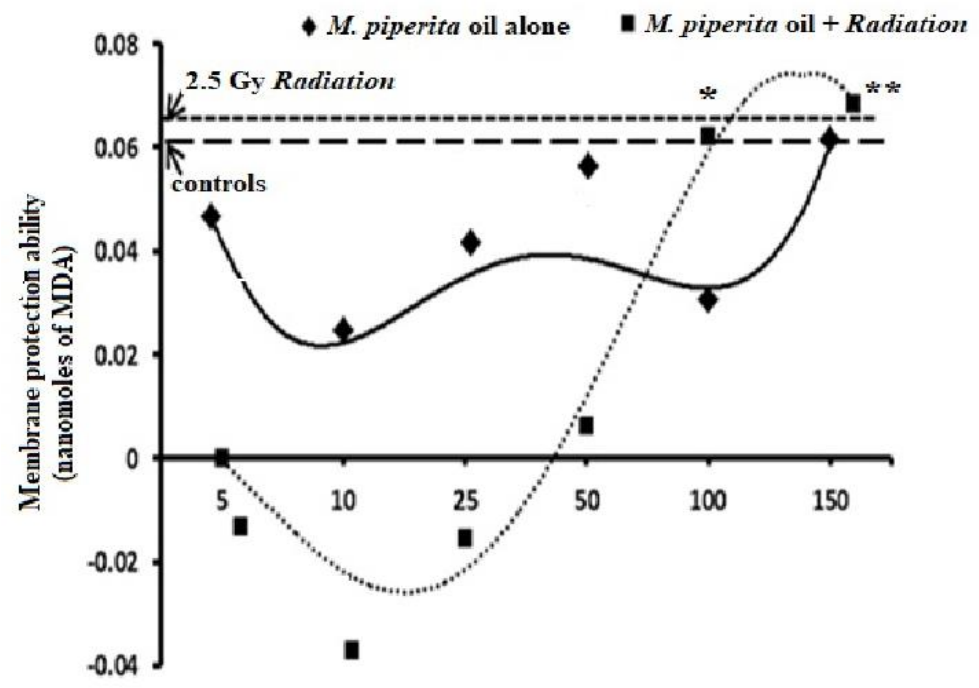

Figure 5. Analysis of the membrane protection ability (\%) of $M$. piperita oil utilizing an artificial membrane system (liposome). The artificial system were irradiated with dose rate $=1.26 \mathrm{KGy} / \mathrm{hr}$, for $3.1 \mathrm{~min}$. A significant $\left({ }^{*} \mathrm{p}<0.04\right)$ decrease in the formation of malondialdehyde (MDA) was recorded at $150 \mu \mathrm{g} / \mathrm{ml}$ of 2.5 Gy irradiated M. piperita samples. The lipid peroxidation activity is expressed as nanomoles of MDA formed. Each experiment was performed in triplicate and was repeated three times.

IR degrades the membranes and walls of the cell and so facilities a more efficient release of the extractable substances [55]. EPR spectra registered in the $M$. piperita oil alone and UVB and 10 Gy irradiation are presented on Figure 6. The spectra registered in $M$. piperita oil alone exhibited almost a symmetrical single EPR spectral line with $g=2.00492 \pm 0.0003$ at $3514 \mathrm{G}$ magnetic field, and EPR signal intensity DI/N- 1.826. The EPR signals registered after UVB $(\mathrm{g}=2.00586 \pm 0.0002$ with a small characteristic splitting) and $10 \mathrm{~Gy}$ $(\mathrm{g}=2.0019 \pm 0.0002)(\mathrm{DI} / \mathrm{N}-1.831$, arbit. units) radiation were different, compared to signal in M. piperita alone. It is suspected, that the radical structure presenting in $M$. piperita alone was affected by both types radiation, without affecting $(\mathrm{p}>0.05)$ the spectra intensity. The emergence of a new radical structure in 10 Gy irradiated M. piperita oil is due the lower g-value. Similar structural alterations after radiation exposure were recorded in Lavandula Angustifolia M., Rosa Damascena L. and Silybum Marianum [56, 57, 58].

DPPH stable radical easily react with in vitro antioxidants and free radicals that possess functional groups donating $\mathrm{H}^{\cdot}$ and these interactions written as:

$$
\mathbf{D P P H}^{\cdot}+\mathbf{R}^{\cdot}=\mathbf{D P P H}-\mathbf{R}
$$

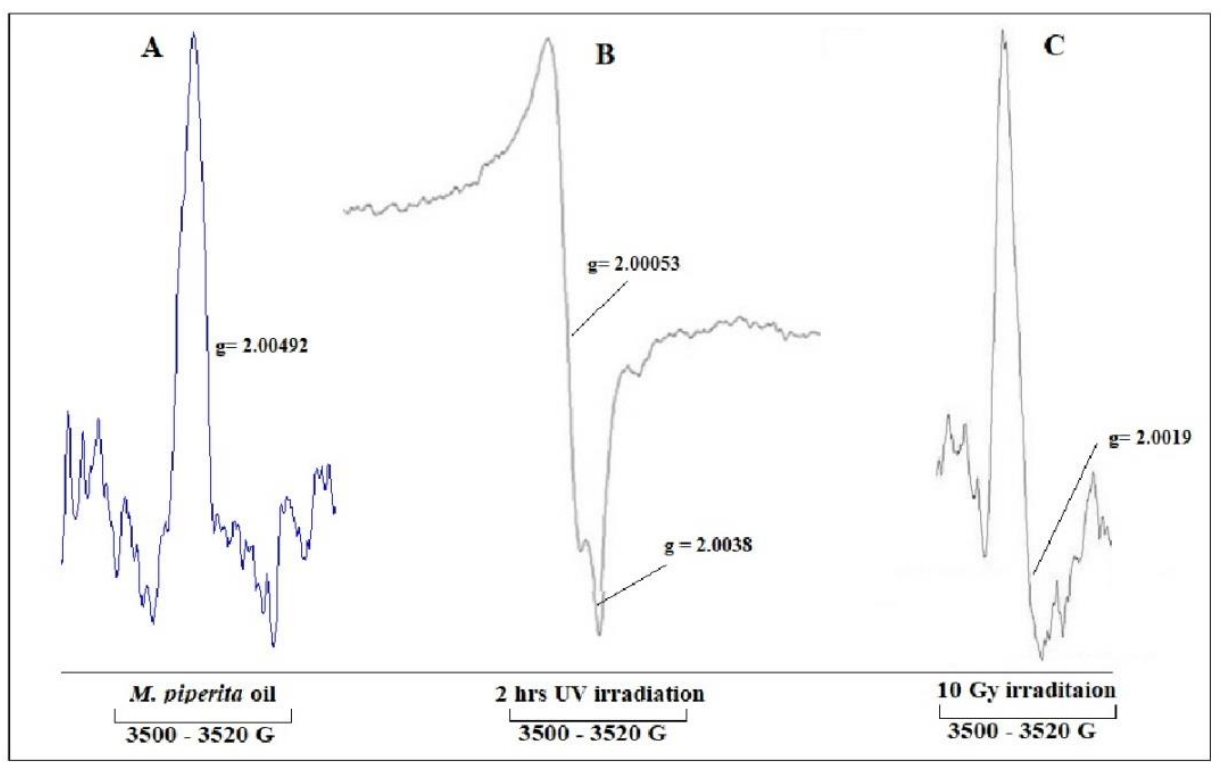

Figure 6. First derivative of the absorption curve (arbit. units) of $M$. piperita oil registered before radiation $(\mathbf{A})$ after $2 \mathrm{~h}$ UVB $(\mathbf{B})$ and $10 \mathrm{~Gy}$ irradiation $(\mathbf{C})$ with respect to the applied magnetic field $(\mathrm{G})$. 
Using the DPPH we have applied a direct EPR method [59] to evaluate and compare the $M$. piperita radical- scavenging capacity alone and after radiation (Figure 7). UVB $(89.97 \pm 0,037$ $\%, \mathrm{p}<0.003)$ and $10 \mathrm{~Gy}$ - irradiated $(94.57 \pm$ $0,09 \%, \mathrm{p}<0.05)$ samples, exhibited 2 times higher scavenging capacity, compared to $M$. piperita alone (48.81 $\pm 0,099 \%)$. Amplification in scavenging ability, present at oil alone and irradiated $M$. piperita samples, might be explained by strong antioxidant activity and
KARAMALAKOVA Y. D. the formation of stable radical in the chemical composition, resistant to IR- oxidation. Samartha et al., 2017 [60] consider that pretreatment of $M$. piperita extract/ oil prior exposure to $\gamma$-radiation in animals has been shown to provide protection against hematopoietic injury in bone marrow, intestine and testis in bone marrow cells and significantly reduced the number of chromosomal aberrations.

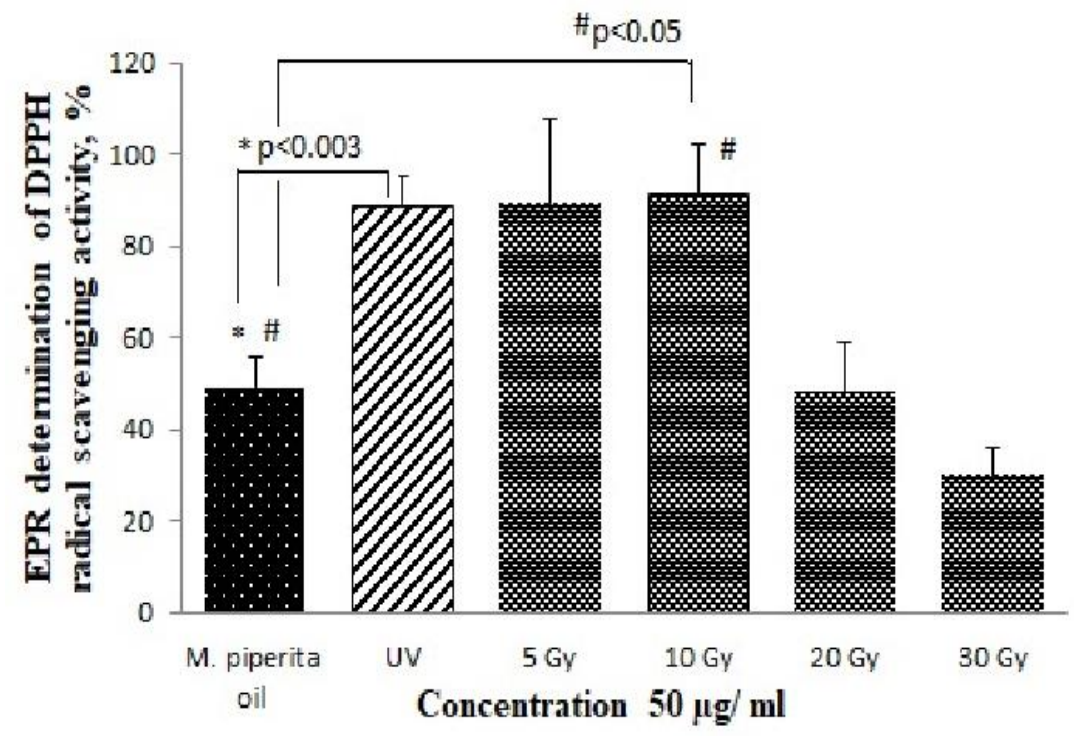

Figure 7. The percent scavenged DPPH radicals of $M$. piperita oil alone, after UVB and 10 Gy irradiation. Results are expressed as mean of replicates (in thrice) from three independent experiments. (*,\#) Significants ( $\mathrm{p}<0.05)$, as compared to oil alone.

\section{CONCLUSION}

For the first time modulatory role of Bulgarian M. piperita oil against radiation-induced oxidative disorders was tested by different in vitro methods. Bearing in mind both, the presence and stability of the new radical structures formed after irradiation and higher protective effect (in the respect of excellent DPPH radical scavenging capacity) we consider oil might be suitable for medicinal treatment, preparation of cosmetics, and as in vitro good antioxidant/ radioprotector, as well.

\section{ACKNOWLEDGEMENT}

This study was supported by a grant of Ministry of Education, Youth and Science Indo-Bulgarian collaborative project (Bin7/2008) and "FINANCING OF FUNDAMENTAL SCIENTIFIC RESEARCH - 2016", (H09/56).

\section{REFERENCES}

1. Jagetia, G.C., Radioprotective Potential of Plants and Herbs against the Effects of Ionizing Radiation. J Clin Biochem Nutr, 40: 74-81, 2007.
2. Halliwell, B., and Gutteridge, J.M., Oxygen toxicity, oxygen radicals, transition metals and disease. Biochem J, 219: 1-14, 1984.

3. Apel, K., and Hirt, H., Reactive oxygen species: metabolism, oxidative stress, and signal transduction. Annu Rev Plant Biol, 55: 373-399, 2004.

4. Halliwell, B., and Gutteridge, J.M.C., Free radicals in biology and medicine. In: Clarendon Press, 1989.

5. Paul, P., Unnikrishnan, M.K., Nagappa, A.N., Phytochemicals as radioprotective agents -A Review. Indian J Natural Prod and Res, 2 (2): 137-150, 2011.

6. Sharafi, S.M., Rasooli, I., Owlia, P., Taghizadeh, M., Astaneh, S.D.A., Protective effects of bioactive phytochemicals from Mentha piperita with multiple health potentials. Pharmacognosy Mag, 6(23):147-153, 2010.

7. Baliga, M.S., and Rao, S., Radioprotective potential of mint: A brief review". J Cancer Res Ther.6 (3): 255-262, 2010.

8. Stanev, S., Основни характеристики на перспективни наши и чужди образци 
Mentha piperita. Юбилейна научна сесия, България, Казанльк, pp 211-215, 2007.

9. Stanev, S., and Zheljazkov, V.D., Study on Essential oil and Free Menthol Accumulation in 19 cultivars, populations, and clones of peppermint (Mentha X piperita). Acta Hort, 149-152, 2004.

10.Stojanova, A., Paraskevova, P., and Anastassov, C., A comparitive investigation on the essential oil composition of two Bulgarian cultivars of Mentha piperita L. J.Essent. Oil Res, 12:438-440, 2000.

11.Aridogan, B., Baydar, H., Kaya, S., et al. Antimicrobial activity and composition of some essential oils. Archives Pharmacl Ras, 25: 860-864, 2002.

12.Jirovetz, L., Wlcek, K., Buchbauer, G., Gochev, V., et al. Chemical Composition and Antifungal Activity of Essential Oils from Various Bulgarian Mentha x piperita L. Cultivars Against Clinical Isolates of Candida albicans. J Essential Oil Bearing Plants, 10(5): 412-420, 2013.

13.Hawthorn, M., Ferrante, J., Luchowski, E., et al. The actions of pepper Mint oil and menthol on calcium channel dependent processes in intestinal, neuronal and cardiac preparations. Aliment Pharmacol Ther, 2:101-18, 1988.

14.Samarth, R.M., and Kumar, A., Radioprotection of Swiss albino mice by plant extract Mentha piperita (Linn.). $J$ Radiat Res, 44:101-109, 2004.

15.Samojlik, I., Petković, S., Mimica-Dukić, N., Božin, B., Acute and chronic pretreatment with essential oil of peppermint (Mentha piperita L, Lamiaceae). Phytother Res, 26: 820-5, 2012.

16.Jagetia, G.C., and Baliga, M.S., Influence of the leaf extract of Mentha arvensis Linn. mint; on the survival of mice exposed to different doses of gamma radiation. Strahlenther Onkol, 178:91-98, 2002.

17.Samarth, R.M., Goyal, P.K,, Kumar, A.. Protection of Swiss albino mice against whole-body gamma irradiation by Mentha piperita(Linn.). Phytother Res, 18:546550, 2002.

18.Cappello, G., Spezzaferro, M., Grossi, L., Manzoli, L., Marzio, L., Peppermint oil (Mintoil) in the treatment of irritable bowel syndrome: A prospective double blind placebo-controlled randomized trial. Digestive and Liver Dis, 39: 530-536, 2007.

19.Pittler, M.H., Ernest, E., PepperMint oil for irritable bowel syndrome: A critical review and meta-analysis. Am J Gastroenterol, 93:1131-151, 1998.
20.Kasem, R.F., Hegazy, R.H., Arafa, M.A., Abdelmohsenm M Chemopreventive effect of Mentha piperita on dimethylbenz[a]anthracene and formaldehydeinduced tongue carcinogenesis in mice (histological and immunohistochemical study. J Oral Pathol Med. 43(7):484-91, 2014.

21.Directive 1999/3/EC of the EP established a Community list of food and food ingredients that may be treated with ionizing radiation, $J$ Europ Comm, L 66: 24-25, 1999.

22. Suhaj, M. and Horvathova, J., Changes in antioxidant activity induced by irradiation of clove (Syzygium aromaticum) and ginger (Zingiber officinale). J. Food and Nutrition Research, 46(3): 112-122, 2008.

23.Karamalakova, Y., Sharma, J., Nikolova, G., et al. Studies on Antioxidant Properties before and after UV-And $\Gamma$-Irradiation of Bulgarian Lavender Essential Oil Isolated from Lavandula Angostifolia Mill. Biotech \& BiotechnolEquip, 27(3): 3861-3865, 2013.

24.Polovka, M., Brezova, V., Stasko, A., Antioxidant properties of tea investigated by EPR spectroscopy. Bioph. Chem, 106: 39-56, 2003.

25.Raffi, J., Yordanov, N.D., Chabane, S., Douifi, L., et al. Identification of irradiation treatment of aromatic herbs, spices and fruits by electron paramagnetic resonance and thermoluminescence. J Spectrochimica Acta A, 56: 409-416, 2000.

26.Troup, G.J., Navarini, L., Liverani, F.S., and Drew, S.C., Stable radical content and anti-radical activity of roasted Arabica coffee: from in-tact bean to coffee brew. PloS ONE, 10: e0122834, 2015.

27.Oyaziu, M., Antioxidative activity of browning products of glucosamine fractioned by organic solvent and thin layer chromatography," Nippon Shokuhin Kogyo Gakkai-Shi, 35: 771-775, 1986.

28.Cuendet, M., Hostettmann, K., Potterat, O., and Dyatmiko, W., Iridoid glucosides with free radical scavenging properties from Fagraea blumei. Helvet Chim. Acta, 80: 1144-1152, 1997.

29.Re, R., Pellegrini, N., Proteggente, A., Pannala, A., Yang, M., and Rice-Evans, C., Antioxidant activity applying an improved ABTS radical cation decolorization assay. Free Rad Biol Med, 26(9): 1231-1237, 1999.

30.Shirwaikar, A., Prabhu, K., and Punitha, I.S.R., In-vitro antioxidant studies of Sphaeranthus indicus. Indian $J$ Experim Biology. 44(12): 993- 998, 2006. 
31.Lasic, D.D., and Papahadjopoulos, D., Medical applications of liposomes. Eds, Elsevier, 1998.

32.Ohkawa, H., Ohishi, N., and Yagi, K., Assay for lipid peroxides in animal tissues by thiobarbituric acid reaction. Analytic Biochem, 95: 351-358, 1979.

33.Santos, A.B., Silva, D.H.S., Bolzani, V.D.S., Santos, L.Á., e al., Antioxidant properties of plant extracts: an EPR and DFT comparative study of the reaction with DPPH, TEMPOL and spin trap DMPO. $J$. Brazilian Chem Soc, 20(8): 1483-1492, 2009.

34.Zheleva, A., Karamalakova, Y., Nikolova, G., et al., A new antioxidant with natural origin characterized by Electron Paramagnetic Resonance spectroscopy methods. Biotech Biotechnol Eq, 26(sup1): 146-150, 2012.

35.Hosseinimehr, S.J., Trends in the development of radioprotective agents. Drug Discov Today, 12: 794-805, 2007.

36.Lobo, V., Patil, A., Phatak, A., Chandra, N., Free radicals, antioxidants and functional foods: Impact on human health. Pharmacognosy Rev, 4(8):118-126, 2010.

37.Gonçalves, R.S.I., Battistin, A., Pauletti, G., et al., Antioxidant properties of essential oils from Mentha species evidenced by electrochemical methods. Revista Brasileira De plantas med, 11: 4. ISSN 1516-0572, 2009.

38.Rahman, M.M., Islam, M.B., Biswas, M., and Alam, A.H.K., In vitro antioxidant and free radical scavenging activity of different parts of Tabebuia pallida growing in Bangladesh. BMC Res Notes, 8: 621, 2015.

39.Hussain, A.I., Anwar, F., Nigam, P.S., Ashraf, M., Gilani, A.H., Seasonal variation in content, chemical composition and antimicrobial and cytotoxic activities of essential oils from four Mentha species. $J$ Science of Food and Agric, 90: 1827-1836, 2010.

40.Mahboubi, M., Kazempour, N., Chemical composition and antimicrobial activity of peppermint (Mentha piperita L.) Essential oil. Songklanakarin J Sci Technol, 36 (1): 83-87, 2014.

41.Bellassoued, K., Hsouna, A.B., Athmounim, K., et al., Protective effects of Mentha piperita L. leaf essential oil against CCl4 induced hepatic oxidative damage and renal failure in rats. Lipids in Health and Disease, 17:9, 1, 2018.

42.Fatemi, F., Dini, S., Rezaei, M.B., et al., The effect of $\gamma$-irradiation on the chemical composition and antioxidant activities of peppermint essential oil and extract. $J$ Essential Oil Res, 26:2, 97-104, 2014.

43.Kaviarasan, S., Naik, G.H., Gangabhagirathi, R., Anuradha, C.V., Priyadarsini, K.I., In vitro studies on antiradical and antioxidant activities of fenugreek (Trigonella foenum graecum) seeds. Food Chem, 103: 31-37, 2007.

44.Singh R, Shushni, M.A.M., and Belkheir, A., Antibacterial and Antioxidant Activities of Mentha piperita L. Arabian J Chem. 8, 322-328, 2015.

45.Jordan, M.J., Lax, V., Rota, M.C., Loran, S., Sotomayor, J.A., Effect of the Phenological Stage on the Chemical Composition, and Antimicrobial and Antioxidant Properties of Rosmarinus officinalis L. Essential Oil and Its Polyphenolic Extract. Industrial Crops and Prod, 48: 144-152, 2013.

46.Delledonne, M., NO news is good news for plants. Current Opinion in Plant Biol, 8: 390-396, 2005.

47.Sanz, L., Albertos, P., Mateos, I., et al., Nitric oxide (NO) and phytohormones crosstalk during early plant development. $J$ Experiment Botany, 66: 10, 2857-2868, 2015.

48.Bhattacharyya, A., Chattopadhyay, R., Mitra, S., Crowe, S.E., Oxidative Stress: An Essential Factor in the Pathogenesis of Gastrointestinal Mucosal Diseases. Physiol Rev, 94(2): 329-354, 2014.

49. Samarth, R.M., Kumar, A., Radioprotection of Swiss albino mice by plant extract Mentha piperita (Linn.). J Radiat Res, 44: 101-9, 2003.

50.Rahal, A., Kumar, A., Singh, V., Yadav, B., et al., Oxidative stress, prooxidants, and antioxidants: the interplay. BioMed res intern. Article ID 761264, 19 pages, 2014.

51.Kma, L., Plant Extracts and Plant-Derived Compounds: Promising Players in Countermeasure Strategy Against Radiological Exposure: A Review. Asian Pac J Cancer Prev, 15(6): 2405-2425, 2014.

52.Sharafi, S.M., Rasooli, I., Owlia, P., Taghizadeh, Ma., and Astaneh, S.D.A., Protective effects of bioactive phytochemicals from Mentha piperita with multiple health potentials. Pharmacogn Mag, 6(23): 147-153, 2010.

53.Kumar, P.I. and Goel, H.C., Iron chelation and related properties of podophyllum hexandrum, a possible role in radioprotection. Indian $J$ Experim Biol, 38:1003-1006, 2000.

54.Samarth, R.M., Panwar, M., Kumar, M., Kumar, A., Radioprotective influence 
of Mentha piperita (Linn) against gamma irradiation in mice: Antioxidant and radical scavenging activity, 82(5): 331-7, 2006.

55.Thariat, J., Collin, F., Marchetti, C., et al., Marked difference in cytochrome $\mathrm{c}$ oxidation mediated by $\mathrm{HO} \cdot$ and/or $\mathrm{O} 2 \cdot-$ free radicals in vitro. Biochimie, 90: 14421451, 2008.

56.Adhikari, M., Karamalakova, Y., Ivanov, V., et al., A comparative evaluation of an antioxidant of natural origin derived from silybum marianum characterized by in vitro assays and electron paramagnetic resonance spectroscopy. Trakia J Sci, 10(1): 17-24, 2012.

57.Karamalakova, Y., Sharma, J., Nikolova, G., Stanev, S., et al., Studies on Antioxidant Properties before and after UV- And $\Gamma$ Irradiation of Bulgarian Lavender Essential Oil Isolated from Lavandula Angostifolia
Mill. Biotechn \& Biotechn Eq, 27(3): 38613865, 2013.

58.Nikolova, G., Karamalakova, Y., Kovacheva, N., Stanev, S., Zheleva, a, Gadjeva, V. Protective effect of two essential oils isolated from Rosa damascena Mill and Lavandula angustifolia Mill, and two classic antioxidants against L-dopa oxidative toxicity induced in healthy mice. Regulatory Toxicol Pharmacol, 81:17, 2016.

59.Mason, R.P., Hanna, P.M., Burkitt, M.J., and Kadiiska, M.B., Detection of oxygenderived radicals in biological systems using electron spin resonance. Environ Health Perspect, 102(10): 33-36, 1994.

60.Samartha, R.M., Samartha, M., Matsumoto, Y., Medicinally important aromatic plants with radioprotective activity. Future Sci. OA. FSO247. 10.4155/fsoa-2017-0061, 2017. 